\title{
Pedagogical Process of Teaching in Higher Education Institutions
}

\author{
Maksudova Mokhigul Usmanovna, Bozorova Viloyat Muzafarovna, Kamoliddinova Vazira \\ Fazlitdinovna
}

\begin{abstract}
Promotion of education and talent is one of the main principles of state education policy and is fully applicable to all stages of continuing education. The students' talents and abilities are encouraged by the state financially and morally. Nowadays pedagogical science is introducing new concepts in the management of educational institutions. For example, the concept of "impact" is used instead of "interaction", "cooperation", "reflexive control". The theory of educational institutions is enriched with educational management theory. The article deals with the educational management teaching process in higher education systems. The article deals with the education process in higher education systems.
\end{abstract}

Keywords : Pedagogical process, teaching, teaching management, higher education institutions, educational management, pedagogical process.

\section{INTRODUCTION}

$\mathrm{I}_{\mathrm{t}}$ will also help the learners to make good use of these achievements and draw their own conclusions and find their place in the future. Article 4 of the Law of the Republic of Uzbekistan "On Education" provides for the nationality, language, sex, age, religious beliefs, social origin, position, type of service, They have the right to education regardless of the length of their stay in the Republic of Uzbekistan. The principle of open access to education within the state educational standards serves to illuminate this situation. The article also states that foreign citizens have the right to education in the Republic of Uzbekistan in accordance with international treaties. The fact that stateless persons residing in the Republic of Uzbekistan have equal rights to education with citizens of the Republic of Uzbekistan means that this principle serves the interests of the individual and his interests. There are educational establishments in the country with general secondary education in Uzbek, Russian, Kazakh, Kyrgyz and Tajik, thus ensuring equal access to education for all nationalities. In addition, there are "Sunday schools" throughout the country, and people of all nations have the opportunity to volunteer in their native language on weekends.

Revised Manuscript Received on October 15, 2019.

* Correspondence Author

Maksudova Mokhigul Usmanovna*, Teachers of Foreign Languages Faculty, Bukhara State University, Uzbekistan

Bozorova Viloyat Muzafarovna, Teachers of Foreign Languages Faculty, Bukhara State University, Uzbekistan

Kamoliddinova Vazira Fazlitdinovna, Teachers of Foreign Languages Faculty, Bukhara State University, Uzbekistan

The uniform and differentiated approach to the choice of educational programs is reflected in Article 7 of the Law of the Republic of Uzbekistan on Education. State educational standards specify the requirements for the content and quality of general secondary, secondary special and higher education.

State educational standards are obligatory for all educational institutions of the Republic of Uzbekistan. This means that for each type of education separate state educational standards are developed, and the requirements of these standards are equally applicable to educational institutions at this stage. However, based on state educational standards, educational institutions can develop and use their own curricula. This shows that the learning objectives are unique, but the ways in which they can be achieved are different.

Promotion of education and talent is one of the main principles of state education policy and is fully applicable to all stages of continuing education. The students' talents and abilities are encouraged by the state financially and morally. Such incentives include awarding gifted students with honorary diplomas, scholarships and awards.

\section{LITERATURE REVIEW}

Adoption of the Resolution of the Cabinet of Ministers of the Republic of Uzbekistan of March 25, 1993 "On Remuneration and Material Incentives for Students of Uzbekistan" provides a legal guarantee for this principle. According to this decision, Olympiads are held every year between students and students, and the winners receive different privileges. According to the Decree of the President of the Republic of Uzbekistan from February 5, 1993 "About measures to stimulate students in Uzbekistan", students with the scientific potential, undergraduate and graduate degrees. and the Presidential Scholarships of the President of the Republic of Uzbekistan for postgraduate students who successfully carry out their research activities are established and each year eleven educational areas (engineering and computer science, medicine, physics and mathematics, economics, journalism, humanities, law) are established. and competitions for the State Scholarship of the President of the Republic of Uzbekistan on International Relations, Pedagogy, Culture and Arts, Foreign Languages, Agriculture). 
In addition, there are scholarships for gifted students named "Beruni", "Ulugbek" and "Navoi", which financially support the activities of their students.

\section{ANALYSIS}

In addition, for the material and moral encouragement of talented youth, to support their education abroad, "Umid", "Istedod", "Republican Children's Fund", "For Healthy Generation". , Ulugbek and other foundations. Currently, more than 2,000 students have been trained abroad to improve their knowledge thanks to the practical support provided by the government. The aforementioned ideas are a clear indication of the fact that in the country the principle of education and promotion of talent is fully implemented. The principle of harmonization of state and public administration in the education system implies cooperation in the management of public and educational institutions in the organization and improvement of the quality of education. Public administration in the education system contributes to the effectiveness of education. Educational systems and types. The education system is a complex of all types of educational institutions, which provide education to the younger generation based on the basic principles of state policy. The education system in each country is closely linked to its socio-political, economic and cultural life.

The educational system of the Republic of Uzbekistan is a state and nongovernmental educational institution that implements educational programs in accordance with state educational standards. - Pedagogical institutions, public administration bodies in the field of education, as well as their enterprises, institutions and organizations. The education system of the Republic is unique and continuous.

According to the Law on Education, education in the Republic of Uzbekistan is carried out in the following types:

Preschool education is a state and non-state pre-school education that ensures a healthy, full-fledged development of a child, encourages him to study, prepares him for regular education, and attends the age of six to seven. the stage of education implemented in institutions and families.

General secondary education is provided in two stages. These are:

1) primary education (Grades 1-4);

2) General secondary education (Grades 1-9).

Elementary education is the stage in which students develop personal hygiene and healthy lifestyle based on the acquisition of basic knowledge, skills, and skills in reading, writing, and computing based on the sophisticated scientific knowledge.

General secondary education provides students with regular knowledge of the fundamentals of science, the need for them to acquire knowledge, basic educational, scientific and cultural knowledge, and moral and ethical qualities based on national and universal values. Stage 1: Formation of skills, creative thinking and environmental awareness, and the choice of profession. General secondary education is provided to students in the I-IX classes on the basics of education in accordance with the state educational standards.

\section{DISCUSSION}

The establishment of specialized schools for the development of children's abilities and talents is important in ensuring their future.

Compulsory secondary specialized vocational education is carried out on the basis of general secondary education with the duration of training for three years. This is an independent type of education that has its own role in the system of continuous education. Secondary specialized vocational education is a voluntary basis established on the basis of general secondary education that provides students with knowledge of one or more of the major specialties in the chosen profession based on their abilities and interests. transfer stage. Education in these institutions is optional for students. The academic lyceum provides secondary special education, legal status in accordance with the state educational standards in order to provide students with a deep, diversified, differentiated, vocational education with their intensive intellectual development taking into account the abilities and interests of students. having an educational institution. Academic lyceums are mainly established at universities. Vocational College provides specialized secondary education within the relevant state educational standards, with the aim of providing students with one or more specialties in their chosen profession, which will enhance their vocational skills, knowledge and skills. legal educational institution providing vocational training.

Higher education is based on secondary special and vocational education and is organized in two stages (bachelor's and master's degree) and provides highly qualified specialists in various fields of national economy. stage of education. A bachelor's degree is a basic higher education, providing basic and applied knowledge in the field of specialization, with at least four years of training. Upon termination of the bachelor degree, graduates will receive a "bachelor's degree" and a diploma that entitles them to a professionally-recognized profession. Master's Degree is a postgraduate education with at least two years of undergraduate education that provides fundamental and practical knowledge of a specific specialty.

Professional Development and Retraining is a training phase established to upgrade and deepen professional knowledge and skills of professionals. According to the results of training at the educational institutions, a state-issued certificate and certificate is issued. Out-of-school education meets individual and growing educational needs of children and adolescents, established in cultural, aesthetic, scientific, technical, sports and other fields. The stage of training to be organized for leisure and leisure activities. Out-of-school education is provided by state bodies, public organizations, as well as other legal and natural persons in out-of-school public and non-state educational institutions. 2. The current state of the education system in the world. We would like to highlight the educational system of the US,

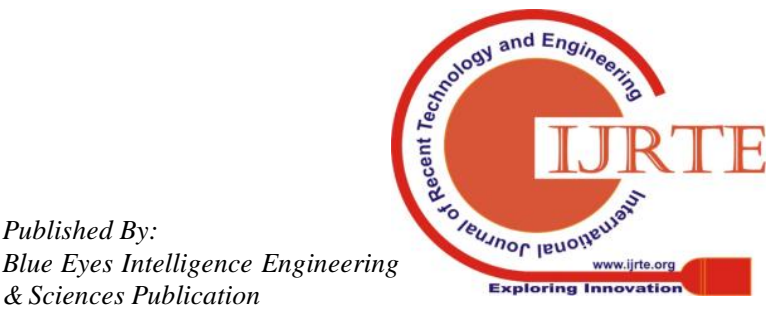


France, and Japan for the purpose of studying advanced educational systems of foreign countries. I. The education system in the United States includes the following steps: 1) pre-school institutions - serve to foster children aged 3 to 5; 2) Primary schools (1-8 grades) - children from 6 to 13 years old; 3) Secondary schools (9th and 12th grades) - provide opportunities for children from 14 to 17 years of age. Secondary school consists of lower and upper secondary schools 4) Higher education - in colleges and universities for 2 or 4 years. 5) Postgraduate and doctoral courses at universities and other universities.

In the US, compulsory education is valid until the age of 16. The educational institutions operating in the country may be state, community, private or religious institutions. There is no uniform curriculum for schools in the United States. Each state has its own curriculum. Accordingly, primary education in the States can be 4, 5, 6 and 8 years.

II. The education system in Japan includes preschools, primary schools, secondary schools and universities.

Children go to kindergarten at the age of 3-5 and are involved in 3, 2, 1 year courses.

Primary school is 6 years old and 6 years old. After completing primary school, the junior high school will teach for 3 years. In Japan, 9 years of education is compulsory and all children are taught for free and use free textbooks.

High school junior high schools are optional in Japan, with day, evening, and extramural forms. The term of study is 3 years.

The effectiveness of the pedagogical process, that is, the effectiveness of the educational process, determines the degree of compliance of subjects with their own development and training in accordance with state educational standards. The complexity and complexity of the challenges of organizing and managing pedagogical processes in the educational institution not only imply a qualitative change in the organization and management of pedagogical processes, but also the need to improve its content. The process of reforming an educational institution usually starts with local, separate, separate, innovations that are not mutually exclusive within the creative and pedagogical activities of some faculty members. Then reform covers areas, industries, sectors and sections. During the reform process, all students, faculty, and administrators will be involved in the full-fledged facility, with new goals and structures focused on development and positive outcomes. There is a need and opportunity to create a kind of educational institution. In this case the educational institution develops as a separate social organism, social system. Achievement of objectives, solution of various problems are carried out using modern methods, results are adapted to modern requirements and efficiency of the pedagogical system is ensured. The culture of an educational institution, which includes approaches, approaches, and procedures to address the existing problems of educational institutions, is an important component of the pedagogical system. There is a need to harmonize the philosophy and culture (management, pedagogical, educational, spiritual) of an educational institution. Internal management of an educational institution, or internal

control, comprised of managers and other community members to effectively organize and manage pedagogical processes. The educational institution team is a complex system that provides for the organization of educational and labor activities, as well as formal and informal, horizontal and vertical, interpersonal and labor relations and relationships. Educational institution as a system object of management activity has the following features: $\bullet$ directions of development based on the need, opportunity, performance indicators of the educational institution and criteria of their own ability; • its potential, functionality, individuality and culture; - integrated educational system of educational institution; - Opportunities to provide scientific and methodological products and ICT tools; - internal opportunities and relationships with the external environment; - Development of the pedagogical and educational community, as well as the internal management system of the educational institution and its development.

In designing and managing pedagogical processes, it is important to consider the importance of the impact of the components that contribute to the development of a holistic pedagogical process and its unique model as a systematic object, and to facilitate the development of pedagogical processes in the same and equal environment. It is necessary to give privileges to change some parts and joints. Changes in the overall model of pedagogical processes should be based on the faculty, students' abilities, their initial notions and beliefs, as the updated model can meet the changing needs of students in changing educational, spiritual, and spiritual needs. It is necessary to use the experience of professors and teachers with the skills and qualifications, to develop their scientific and creative potential, and to create the necessary conditions for the use of ICT tools. The following basic principles must be taken into account: - Successful development of pedagogical processes depends on the abilities of the subjects, the ability of teachers to see and to avoid them when the ways of the development of the pedagogical processes are defined in random and predictable ways; - the need for coordination and coordination of development of all the components that constitute it, as well as the integration of the subjects' relationships and activities, for the successful development of the pedagogical process as a systematic object; - The success of pedagogical processes depends on the ability of faculty members to foresee the future and anticipate development opportunities based on existing factors;

- Inability to define complex developmental pedagogical processes without the needs and capabilities of development, the ability of the subjects to understand the abilities and basics of development; - inability to provide effective pedagogical processes based on strong, compulsive and comprehensive methods of action; • Clearly localized effects on constituents and divisions can serve as a basis for successful development of pedagogical processes. 


\section{Pedagogical process of teaching in higher education institutions}

Reflexive approach plays an important role in coordinating the activities of subjects in pedagogical processes as an important mechanism for their independent and effective thinking. Separate the processes of explaining the concepts learned during the reflexive approach in the context of a broad system (assessing emerging situations and the behavior of subjects, identifying ways and directions for effective performance of tasks), self-analysis of subjects It creates conditions for active thinking about one's own concepts and actions. A person-centered approach to the organization and management of pedagogical processes is also needed, as a way to ensure that subjects are actively involved in pedagogical processes and motivate subjects to achieve specific goals. In the personality-activity approach, the components of personality and activity are closely interconnected, because in the pedagogical processes organized on this basis, students act as subjects and, in turn, the development of the student's personality as a subject, the development of independent, free, critical, analytical and effective thinking.

The rapidly changing nature of pedagogical processes and activities dictates the need to focus on the implementation of another methodological approach, that is, the use of an appropriate method of managing the internal and external conditions of the controlled entity. This implies a situational approach to the organization and management of pedagogical processes. The situational approach is to determine the effectiveness of the pedagogical process according to specific situations. Coordinating the activities of entities is one of the most effective ways to deal with emerging situations. Coordinating the activities of the subject (students) in the context of specific and internal conditions of the pedagogical process, which is a controlled object, helps to ensure the effectiveness of the process. In the situational approach, it is important to consider the following:

- Study, analyze and objectively evaluate the situations in the pedagogical process in order to identify the factors that are important in improving the pedagogical process; • Predicting the effectiveness of the results in different pedagogical situations; - Determine the ways in which subjects can be actively involved in the planning of pedagogical processes and the organization of activities on the basis of a prediction of the factors influencing this process and possible situations. Simply put, the implementation of a coordinated approach saves the time and effort required to ensure the activeness of the subjects and the effectiveness of the pedagogical process, as well as elimination of bias in the pedagogical processes (the teacher's role as a subject alone). . The basic idea of this approach is that no process, including the pedagogical process, is of any value in itself. The importance of pedagogical processes is reflected in its effectiveness, and its effectiveness implies different developments based on the coordination and functioning of subjects.

\section{CONCLUSION}

The results achieved by the introduction of ICT tools can be achieved through the coordination of activities of the subjects of pedagogical process and their activity. This process ensures that subjects are self-guided and creative in their activities by explaining to each participant the purpose and meaning of the concepts learned.

\section{REFERENCES}

1. Abdullayeva SH, Akhatova D., Sabirov B., Sayitov S. Pedagogics. T: Science, 2004

2. Sh.Abdullayeva, H.Ibragimov. Text of lectures on "Theory and history of pedagogy" T: Science, 2004.

3. Abdurakhmanov Abdulkhay. Knowledge that leads to happiness.-T .: Movarounnahr, 2004. -708 p.

4. Abu Ali Ibn Sina Monday: «Irfon», 1980. - 420 p

5. Abu Abdullah Muhammad ibn al-Bukhari. Hadith (Al-Jami 'as-Sahih). Volume 1 Translated by Z.Ismoilov. $-\mathrm{T}$. editorial office of encyclopedias, 1997. $572 \mathrm{p}$

6. Azarov YU.P. Methodology of educational work. -T .: "Teacher", 1991 $67 \mathrm{p}$.

7. Aliyev A. Spirituality, values and art. -T .: Academy, 2000. - 631 p.

8. Akhmedov B. Teaching of ancestors. Proverbs. Stories. Principles. -T .: "Cholpon," 1991. 234 p.

9. Examples of Hadiths on Morals and Ethics Edited by T. Yuldashev - T: Science, 1990. - 146 p.

10. Askar Zunnunov. History of Uzbek Pedagogy. -T .: "Teacher", 1997. 271 p.

11. Askar Zunnunov. Theory of Pedagogy. -T .: "Communication", 2006. $163 \mathrm{p}$.

12. Berdiyev G. Characteristics of interpersonal relations in students. // Public Education, No. 6. 1998. pp. 61-65. 